\title{
LOS LIEDER DE JOSÉ MARÍA EGUREN (1874-1942) COMO DISPOSITIVO POÉTICO
}

\author{
Hervé Le Corre \\ Université de Caen
}

El objetivo de este estudio no es identificar una forma (métrica), el lied egureniano no lo es, ni analizar una serie de poemas (los nueve lieder escritos por el poeta peruano) sino ver cómo una forma socializada - el lied - se actualiza en una obra, la de Eguren, constituyendo un dispositivo, de escritura y de lectura, que cumple con el propósito de lo literario: el texto como disponibilidad, devenir.

\section{A LA ANTIGUA DAMA MÉTRICA (CONSIDERACIONES PREVIAS)}

El estatuto concedido a la métrica no podía seguir separado de las reflexiones modernas sobre teoría y prácticas del texto poético. Urgía sacarla, primero, del exiguo papel de repertorio formal al que se le 
había condenado a menudo, esa taxonomía de lo estable que pregonaba la Identidad, la Simetría y la Isocronía. De ello eran conscientes, por supuesto, tanto Pedro Henríquez Ureña (1961) como Tomás Navarro Tomás (1956) o Rafael de Balbín (1962). Sin embargo, para tomar un solo ejemplo, en la Métrica de Navarro Tomás sigue dominando el modelo binario tradicional - grosso modo la alternancia de un período acentuado con uno no-acentuado- y la referencia a modelos de versos, en realidad especies de arquetipos de versos cuyo número, forzosamente reducido, contrasta con la multitud de las realizaciones efectivas (¿quién no recuerda las 171 combinaciones prosódicas del endecasílabo repertoriadas por el eximio metricista en Los poetas en sus versos ?). Nociones como las de acentos extrarrítmicos o antirrítmicos (Balbín Lucas, 1962) indican otras tentativas para integrar sistemáticamente los «accidentes» acentuales, pero siempre con el ideal de la alternancia a la vista.

Obviamente la situación ha cambiado: la inclusión de la métrica tradicional en una reflexión más amplia, la que concierne a la poética general, permite tomar en cuenta, en la construcción del verso, elementos tan importantes como su estructura fonética, sintáctica y semántica. Para simplificar el proceso que se está llevando a cabo, podría acaso decirse que estamos pasando de una métrica aritmética a una rítmica generalizada. Este proceso tampoco es nuevo: como ha señalado José Domínguez Caparrós (1988), fueron los rusos (de Lotman a Jakobson) quienes fomentaron con más ahínco esa necesaria integración de todas las dimensiones significantes del verso.

Más recientemente, un libro como el de Henri Meschonnic, Critique du rythme. Anthropologie historique du langage, desgraciadamente no traducido todavía al castellano ${ }^{1}$, confirma la magnitud de los cambios que se están verificando. El poeta y crítico francés escribe así, con su habitual rotundidad: «Le rythme est trop important dans le langage pour le laisser à la métrique. La métrique mesure des temps qui ne sont à personne, car ils ne sont pas le temps du sens, le temps des sujets» (1982: 521).

En la perspectiva abierta por Emile Benveniste, Henri Meschonnic apuesta, pues, por una filosofía, una antropología del sujeto, una

\footnotetext{
1 Mientras tanto el lector español puede leer «Transformar la teoría del ritmo ¿por qué y para qué?», un compendio de su ideario, en Ritmos, métricas, rupturas en la poesía hispanoamericana, G. Areta Marigó, H. Le Corre, M. Suárez, D. Vives (eds.) (2000). Madrid: Verbum.
} 
semántica generalizada, la del discurso, en contra de la división engendrada por la ruptura del signo. En el capítulo V de su libro («Le rythme sans mesure»), Meschonnic propone un tipo de lectura prosódica y rítmica que obvia la referencia (y deferencia) tradicional a los modelos de verso. Ese «rythme sans mètre» que propugna Meschonnic (un «mètre» que suena en francés como «maître»: «amo, maestro») implica asimismo la desaparición de la versificación tradicional, o sea la contestación del lugar central del verso en la construcción poética a favor de una unidad mayor, la del poema. Un paso en ese sentido lo había dado Rafael del Balbín (1962) al considerar como básica la unidad estrófica, pero la estrofa seguía siendo una extensión (problemática, es cierto) del sistema, originada por la unidad del verso. Meschonnic prefiere referirse a una unidad semántico-rítmica que no acata las leyes métricas tradicionales.

Hay opciones menos categóricas que las de Henri Meschonnic, y no por ello vergonzosas, así la de José Domínguez Caparrós (1988, 1999), que conserva las nociones de modelo de verso y la de tensión entre una lectura rítmica y otra, más cercana a la de la prosa. La diferencia entre las lecturas que acatan el modelo métrico y otras, más cercanas al habla cotidiana, permiten poner de manifiesto el complejo fenómeno de la recepción histórica de los textos poéticos o los problemas de percepción de algunos elementos sistémicos, como el encabalgamiento (Domínguez Caparrós, 1999: 32-43). Con ello se marca, además, la presencia, histórica y social, de la métrica como rama de la rítmica. No faltan, por otra parte, los argumentos a favor de la permanencia, bajo alguna forma, de los modelos de verso, siquiera fuese la propia experencia de los poetas, como el famoso ejemplo de Paul Valéry que afirmaba haber escrito su «Cementerio marino» impulsado por el peculiar ritmo del decasílabo francés.

¿Ello significa que se deba reincidir forzosamente en la identificación de modelos de verso? Me parece más fructífera la hipótesis de que la existencia de un modelo previo es una abstracción o que, en todo caso, su supuesta anterioridad (¿en el sentido platónico?) no significa para nada una obligatoria repetición, una identidad del verso a sí mismo, a su clasificación arquetípica. Antes que las semejanzas superficiales entre los versos o las formas estróficas, importan sus diferencias profundas (ahí estaría el ritmo). No sólo por las posibilidades (variantes, parodias, evolución...) que brinda esa diferencia esencial, sino por su efectiva incongruencia, por pertenecer los poemas a sistemas sincrónicos y diacrónicos diferentes. ¿Qué relación hay, por ejemplo, 
entre el endecasílabo de Garcilaso y el «hirsuto» de Martí? ¿entre el alejandrino de Berceo y el de Darío (malgré lo que éste dijo)? ¿significan lo mismo la décima española, de origen culto, y la hispanoamericana, marcadamente popular? Podrían multiplicarse los ejemplos.

La estética de la recepción, las recientes teorías pragmáticas, de los sistemas (Maldonado Alemán, 1999), etc., son otras tantas posibilidades de renovación de los estudios sobre la métrica. Actualmente, en términos generales, se están multiplicando los esfuerzos por precisar el lugar y la función del texto literario en el sistema de la comunicación. Ello supone no sólo tener en cuenta elementos tan importantes como las condiciones (diacrónicas y sincrónicas) de recepción / percepción de los textos como las estrategias autoriales (conscientes o no) que presidieron a su elaboración. Parte de ese trabajo se hace, por supuesto, con criterios comparativos, que apuntan a racionalizar lo que de determinación y de innovación pueda haber en la emisión / recepción de tal o cual forma. Esa contextualización de las formas poéticas supone un paso fundamental en un acercamiento más dinámico a la métrica. El no reducir lo textual a lo lingüístico significa también abrir la literariedad a dimensiones socio-culturales no siempre tenidas en cuenta.

Ese amplio campo de posibilidades que se abre al investigador no debe ocultar, sin embargo, las dificultades teóricas que subsisten: volver a situar el texto literario en el contexto de la comunicación (es decir, precisando sus circunstancias antropológicas) ¿significa que aquél «comunique» como cualquier otro hecho lingüístico, con sus instancias definidas y situadas? El ser un artefacto «literario» ¿no implica más bien un modo específico de comunicación caracterizado por Jean Bessière (1990) a través del doble proceso de la descontextualización-recontextualización? La heterogeneidad del texto literario ¿permite que se le atribuyan instancias (emisoras / receptivas) estables? Lo esencial, más allá de cualquier racionalización ¿no sería su perpetua y fecunda alteración?

El devenir otro del texto literario (el movimiento por el cual se hace partícipe de nuestro presente) parece implicar que cualquier análisis que se haga de sus estructuras, así el análisis métrico, fracase fructíferamente, por decirlo así. Permite que se experimente la imposibilidad de cualquier reconstrucción sistemática de carácter «arqueológico» y que se verifique la fecundidad de los desplazamientos inscriptos en el texto literario. Analizar las formas rítmico-métricas del poema es actualizar ese movimiento por el cual se nos escapa. Concluir, para decirlo con Lezama Lima, a la necesidad de un «sujeto metafórico» que afirme «la no identidad de dos formas aparentemente concluyentes» $y$ «destruy[a] 
el pesimismo encubierto en la teoría de las constantes artísticas [...] el pseudoconcepto temporal de que todo se dirige a lo contemporáneo» (1957: 18).

El estudio de la serie de los lieder del poeta peruano José María Eguren (1874-1942) intenta mantenerse entre los dos polos evocados: el de la tentativa de descripción y análisis, en el campo literario, de una «forma»; el de las posibilidades poéticas que se abren paso a través de esa forma y que permite que se hable de «dispositivo» ya que éste dispone y deja disponibles, abiertos a las lecturas, los componentes textuales. Este dispositivo constituye quizás su proyección utópica, ese «silencio» donde «el álbido poema fuga leve» («Patética», Rondinelas).

\section{BALADAS Y LIEDER EN LA POESÍA DE HABLA ESPAÑOLA (ESPAÑA-PERÚ)}

Son nueve los lieder publicados por José María Eguren ${ }^{2}$ a lo largo de su obra, los cuatro primeros pertenecen a su poemario inicial, Simbólicas, de 1911, el siguiente, el «Lied V», es el único de La canción de las figuras (1916), los cuatro últimos forman parte de Sombra, cuyo-manuscrito es también de 1916 pero que se publicó, parcialmente, en antologías de 1924 y 1929.

La elección del lied por parte del poeta peruano sugiere inmediatamente al lector una especie de «anacronismo». En efecto, la aparición del lied, y en general de la poesía de origen alemán (incluso cuando es una adaptación, como es el caso de la balada, de origen inglés) en los países de habla castellana se remonta principalmente, como se sabe, a la segunda mitad del siglo XIX. Si Gustavo Adolfo Bécquer (con Ramón de Campoamor) representa obviamente el hito esencial de esa «germanización» de la poesía castellana, la introducción de la poesía alemana se produce a principios de los años cincuenta por dos vías esen-

${ }^{2}$ Las Obras completas de Eguren fueron publicadas en Lima, por Mosca Azul en 1974. Cito según esta edición. El lector español encontrará una buena antología de sus poemas en Visor (José María Eguren. De simbólicas a Rondinelas, Gema Areta ed., 1992) aunque con unos fallos, como la ausencia, en el índice, del poema «Las torres» (de Simbólicas) o errores como el título «La tarde» por «La tarda» (Ibid.). Léase también: Areta Marigó, G. (1993). La poética de José María Eguren. Sevilla: Alfar. Acabo de tener acceso a la edición reciente de las Obras completas, de Eguren, con material gráfico (Lima: Banco de Crédito del Perú, «Biblioteca Clásicos del Perú», 1997). 
ciales: la de la imitación y la de la traducción. Jorge Urrutia (1995) recuerda así el impacto de la balada alemana en el poemario Baladas españolas (1853) de Vicente Barrantes. Unos pocos años después aparecen las famosas (por su supuesta influencia en Bécquer) traducciones realizadas por Eulogio Florentino Sanz (1822-1881) (Díez Taboada,1958) de algunos poemas del Intermezzo de Heine. Esa traducción, unos años posterior a la de Gérard de Nerval (1848), coincide por otra parte, como lo subraya Jorge Urrutia, con la aparición de las partituras de lieder en los salones de la península (1995: 157).

Si las Baladas de Barrantes resultaban una imitación algo superficial de la forma de la balada (Urrutia, 1995: 95), sin que ésta consiguiera diferenciarse claramente del romance, las traducciones de Sanz implican la irrupción de formas sintéticas y carentes de la retórica vigente entre muchos de los poetas españoles del período. Nerval había elegido la prosa para traducir a Heine, Sanz sigue los cauces de la métrica nacional. Sin embargo, si bien predomina el romance entre los modelos elegidos por Sanz, no escasean otras formas, como estrofas en las que alternan endecasílabos y hepta - o pentasílabos, o estrofas compuestas de decasílabos solos (por ejemplo bajo su forma yámbica, de dos hemistiquios, que reaparecerá en Bécquer) o combinados con octosílabos (en la traducción del famoso «Die Rose, die Lilie...» del Intermezzo).

En 1873, Manuel María Fernández y González publica una serie de traducciones del mismo Heine: esta vez pueden leerse en castellano en la península no sólo el Intermedio sino Regreso y Nueva primavera. Se completa así la labor emprendida por Sanz, siempre a través de la variedad de formas métricas y privilegiando las asonancias. El libro en su segunda edición (de 1878) se enriquece con una serie de recortes de prensa que indican una creciente conciencia de los cambios que se están promoviendo: F. Miguel y Badía defiende las «cualidades prosódicas» del alemán, su riqueza consonántica frente a los usos de los españoles «acostumbrados a vocalizar a borbotones» (Heine, 1878 [1873]: 190) y alaba la precisión de creaciones poéticas sin ripios y con «epítetos [que] son tales y no adjetivos amontonados» (1878 [1873]: 190). El propio Fernández y González, en una nota a la traducción de «Die Heimkehr» escribe:

Lo que impresiona en estas breves estrofas es la manera, el procedimiento, esa forma objetiva donde no se trasparenta el pensamiento ni la emoción del poeta: es un género descriptivo, pictórico por decirlo así, poco usado en las literaturas meridionales (1878 [1873]: 122). 
Ahora bien, por los mismos años en que se está difundiendo el lied y la balada en la península, aparecen en Hispanoamérica diversas traducciones de Heine. La más conocida (y la mejor, según Menéndez Pelayo) es la del venezolano Pérez Bonalde - también famoso por su versión de «El cuervo» de Poe-que traduce el Intermezzo en 1877 y el conjunto del Cancionero en 1885 (Pérez Bonalde: 1964). Habría que cotejar esos textos con sus equivalentes españoles, digamos solamente que siguen dominando las asonancias (con numerosas excepciones) y cierta variedad métrica (abundan los endecasílabos, a veces combinados con heptasílabos, y los octosílabos, pero hay poemas de decasílabos, dodecasílabos o alejandrinos).

El peruano Manuel González Prada, por su parte, traduce también numerosos poemas de Goethe, Heine, Uhland, Kerner, Chamisso, etc. (Ferrari, 1993), publicados en revistas limeñas de la época, antes de pasar a formar el libro segundo (póstumo) de sus Baladas compuesto, pues, según Luis Alberto Sánchez, entre 1871 y 1879 (González Prada, 1989). El peruano elige en la mayoría de los casos, para verter las baladas al castellano, la forma del romance, dividido en estrofas (de cuatro o más versos), con algunas excepciones como la traducción del «Nelumbio» de Heine, un poema de tres cuartetos, el primero de octosílabos, el segundo eneasílabo, el último decasílabo, con estructuras acentuales simétricas que habría que relacionar con su Ortometría y las notas finales de Exóticas.

La reflexión de González Prada sobre la poesía y la lengua alemana se prolongará en su «Conferencia en el Ateneo de Lima» (1886), recogida en Pájinas libres. En ella sitúa a Heine y a Bécquer. Este, después de Barrantes, Ferrán y Ventura Ruiz Aguilera, según González Prada «va jermanizando la poesía castellana [...]. Con [...] su espresión parca i hasta económica, se levanta como un revolucionario para reaccionar contra la intemperancia verbosa de los poetas españoles» (1985: 43). «Injenuidad», «trasparencia» y «delicada ironía» dan a su obra «todo el sabor del lied alemán». Sigue González Prada:

\footnotetext{
A más de la poesía subjetiva del Intermezzo lírico, abunda en Alemania la poesía objetiva de las baladas. ¿Por qué los jermanistas castellanos no aclimatan en su idioma el objetivismo alemán? [...] Ya que nuestra poesía carece de perspectiva, relieve, claroscuro i ritmo ¿por qué los poetas no estudian la forma arquitectónica, escultural, pictórica i musical de Goethe? (1985: 46).
}

Obviamente (y las líneas dedicadas a Heine lo aclaran) el peruano prefiere esta modalidad, la arquitectura objetiva de la balada, a las formas 
más breves y líricas del Intermezzo. Se queja sobre todo González Prada de que «va cundiendo en el Perú el gusto por las rimas de dos cuartetas asonantadas», a imitación de Heine y Bécquer: «ayer imitamos a Quintana, Espronceda, Zorrilla, Campoamor, Trueba i hoi continuamos [...] con Heine i Bécquer» (1985: 36). En 1889, en «Notas acerca del idioma», vuelve a insistir sobre «l'asombrosa flexibilidad del idioma alemán [que] se manifiesta en la poesía»: «los poetas jermánicos $[\ldots]$ no admiten el lenguaje convencional de la poesía, i como los ingleses, cantan con admirable sencillez [...]. Mientras en castellano el poeta se deja conducir por la forma, en alemán el poeta subyuga rima i ritmo» (1985: 266).

Ese recorrido, esquemático e intercontinental, permite apuntar algunas convergencias en torno a la recepción del idioma y de la poesía alemanes en dos países de habla española, el papel estratégico de esa adopción frente a formas autóctonas ampulosas, las posibilidades que se abren de expresión sintética, otras propuestas prosódicas y semánticas. Por lo que va de Hispanoamérica, se prosigue así una reflexión iniciada después de las Independencias (con Bello o Sarmiento), que se anticipa claramente a la actitud del modernismo, de apertura todavía mayor hacia una intertextualidad generalizada y contaminadora.

\section{LOS LIEDER EGURENIANOS Y LO ALEMÁN}

Todo arte es poético; un vuelo fino y absoluto; su libertad corta la red, la métrica y la rima son sus pajes. El ideal sería prescindir del número y la forma (Eguren, 1974: 311).

Es conocida la amistad entre González Prada y Eguren (abril, 1970: 23-26) y las afinidades entre un libro como Exóticas (1911) de aquél y los poemarios de éste (Núñez, 1932: 71-74). González Prada había escrito, además de sus traducciones, una serie de poemas titulados «Lieder de Jorge Balder», recogidos mucho después en Cantos del otro siglo (1979) y en su poesía original se verifica la impronta de la poesía germánica, desde una de sus «Gacelas» (de Exóticas), con cita de Heine, a «Gunnar» (Ibid.), inspirado en las Eddas. Es probable que la fascinación de Eguren por lo alemán, tanto bajo formas (los dodecasílabos de «Eroe» o «La walkyria», en Simbólicas) que recuerdan la manera de Jaimes Freyre (Castalia Bárbara, 1899), como por la 
atmósfera próxima a la balada germánica que subsiste en muchos de sus poemas, tiene que ver con el interés manifestado por González Prada. En las poesías de éste asoma el mundo de la poesía alemana, su medievalismo, sus brumas, su topografía (terrestre / acuática), etc. que volveremos a encontrar en la poesía de Eguren.

La presencia de lo alemán resulta, sin embargo, más difusa en Eguren. Este no conocía el idioma alemán, no existe en su obra, en todo caso, una filiación filológica equivalente a la que se verifica en González Prada. La obra de Eguren, posterior a esa primera aclimatación de la poesía alemana, se aleja más claramente de sus modelos. Se distancia de la narratividad de la balada tradicional, o sugiere otro tipo de narratividad, más laxa o dispersa. No le preocupa encontrar un equivalente a la balada (como lo hace González Prada con sus estrofas arromanzadas) o a las formas sintéticas del Intermezzo (como lo intentan sus traductores españoles, lográndolo perfectamente Bécquer). La serie de los lieder egurenianos corresponde a otra motivación, declaradamente musical, interna. En este sentido Eguren es, por supuesto, el heredero de los modernistas, tanto de su ideología de lo musical (la armonía pitagórica) como de la soterrada presión de lo fónico-pulsional en su prosodia, pero lo hace según coordenadas propias ${ }^{3}$.

El lied egureniano, seriado (del «Lied I» de Simbólicas al «Lied IX» de Sombra), corresponde a un proyecto poético cuyas características quisiera analizar en su relación con lo musical y en tanto producción en serie. Aunque tomaré en cuenta el conjunto de los nueve lieder publicados por Eguren, los cuatro primeros —de Simbólicas - serán los referentes principales.

\section{EL LIED COMO CONTEXTO DE ENUNCIACIÓN}

Hemos afirmado que la elección del lied como modelo (incentivo) por Eguren resultaba algo anacrónica. Desde el punto de vista de la creación poética ello no significa sin embargo gran cosa, por poco que se abandonen las teleologías habituales. En diversos textos suyos

$3 \mathrm{El}$ «anacronismo» de los lieder desempeña, de nuevo, un papel diferenciador, que singulariza a Eguren. En efecto, tras un recuento rápido y parcial, he logrado localizar unos raros poemas modernistas con ese título (uno en Gutiérrez Nájera, de 1877, uno en Darío, de 1890 (?), y un poema de Tablada, titulado «Lieder», de 1892). 
(publicados entre 1930 y 1931 y reunidos después bajo el título de Motivos), que oscilan entre el ensayo y la prosa poética, el poeta peruano deja constancia de esa voluntaria anacronía, mejor dicho, de su voluntad de obviar lo cronológico. En varios de esos Motivos alude de manera admirativa a Milhaud, Honneger, Strawinsky o Prokofieff (hará otro tanto refiriéndose a la pintura de Ernst, Picasso o Dalí), pero sus preferencias íntimas van más bien hacia los Nocturnos de Chopin, hacia Mendelssohn, Schumann, Schubert, Weber o Beethoven. Estos nombres son los que aparecen en sus poesías: «las baladas de Mendelssohn claras» («Rêverie», Simbólicas); «memorias trayendo de Weber lejano» («El pelele», Ibid.); «la canción de Schumann vesperal» («Lied $\mathrm{II} »$, Ibid.), etc.

Lo musical cunde por toda la producción poética de Eguren, siempre en relación con la música romántica: de la «Marcha fúnebre de una Marionnette» (Simbólicas) a los dos «Nocturnos» (sin numerar) de La canción de las figuras y Rondinelas o las dos «Baladas» (tampoco seriadas) de Sombra y Rondinelas. El lector español no podrá dejar de recordar al respecto las afinidades, por lo menos de superficie, entre Eguren y el primer Juan Ramón de Arias tristes, donde aparecen partituras de Schubert, de Jardines galantes, dedicado «a la divina memoria de Enrique Heine», con partituras de Gluck, Schumann y Mendelssohn, o el mismo Juan Ramón de las 26 baladas primaverales.

El lied parece servirle a Eguren, primero, como dispositivo de enunciación, no sólo por su referencia inmediata a lo musical, sino por la especie de voz íntima o menor que el lied contribuye a escenificar. Ese tono menor, que caracteriza buena parte de la llamada poesía posmodernista, aparece como un contrapunto a las voces mayores del último modernismo: la de los Cantos de vida y esperanza darianos, la orquestación chocanesca de Alma América (1906), las Odas o Cantos motivados por el Centenario argentino. Si bien ello no significa que aquellos poetas (Darío sobre todo) no tuviesen capacidades para ensayar ese tono menor, no deja de ser significativo un contraste como el que se da en el segundo número de Colónida (feb. 1916), entre el artículo dedicado a Eguren - que acaba con una cita de su «Lied V»- y la «Sinfonía heroica» de Chocano, publicado en la página siguiente.

Reveladora también es la figura del Eguren lector recordada por Alberto Ureta: «recita a media voz y musitando las palabras sus rimas oscuras, difíciles, susurrantes» (Silva-Santisteban, [1929] 
1977: 85). Basadre en sus Equivocaciones (1928), después de referirse a la «orquesta» de la poesía dariana, escribe: «La música de Eguren evoca sólo a un intrumento pero arcaico. Es una armonía a la sordina [...]. No parece que estuviera escrita en castellano por la tradicional rudeza de este idioma que [sic] Unamuno llamara huesudo» (1928: 27). La frase de Basadre, «no parece que estuviera escrita en castellano», por hiperbólica que pueda resultar a los lectores actuales, recoge de hecho la manera cómo se «oía» la voz egureniana, el desconcierto del público frente a esa poesía «inelocuente», en el sentido de Unamuno ${ }^{4}$, frente a su sintaxis retorcida, a sus pautas musicales sutiles (por ejemplo su discreto anisosilabismo), en desfase con las costumbres del martilleo de los recitales que imperaba todavía en Hispanoamérica.

El primer efecto del lied egureniano está, pues, en esa (re)contextualización de la enunciación: la búsqueda de un lector / oyente condicionado a la vez por una musicalización extensiva e impelido por las exigencias de una audición renovada. $O$ sea una descontextualización respecto de los hábitos nacionales: el referente inicial del lied (tradición e idioma exógenos) confirman el descentramiento dinámico que impulsa la poética egureniana, fiel en ello a los ideales modernizadores de González Prada. El lied como dispositivo poético propone nuevos protocolos de transmisión y de escucha en un marco intertextual también polifónico.

Si nos centramos ahora en los lieder de Eguren en tanto forma y sentido, lo primero que salta a la vista es la ausencia de un patrón métrico o rítmico uniforme. La balada o los lieder tampoco ofrecían esa uniformidad: aunque predominaban en su traducción al castellano las formas arromanzadas para las baladas, eran múltiples las adaptaciones ocasionadas por los otros tipos de poema (como los de Heine), si bien, muchas veces, se volvía a los cauces autóctonos. Pero tampoco puede decirse que los otros casos que demuestran más inventiva, o las formas becquerianas (como esas cuartetas asonantadas cuya imitación denunciaba González Prada), tengan una impronta clara en los lieder de Eguren.

Describamos rápidamente la estructura métrica externa de los nueve poemas:

${ }^{4} \mathrm{He}$ analizado en otro lugar (Poesía hispanoamericana posmodernista. Historia, teoría, prácticas. Madrid: Gredos, B.R.H., 2001, por publicar) el prólogo de Unamuno a Alma América de Chocano, donde reitera su interés por la poesía de los musing ingleses y habla de su propia poesía «inelocuente, conversacional y soterraña» (p. XIV). 


\section{Simbólicas}

- El «Lied I» se compone de 6 estrofas de tres versos (4/11/10 sílabas), llevan rima asonante aguda los últimos versos de cada dos estrofas (en «u» las dos primeras, en «o» las dos siguientes, en «i» las últimas).

- El «Lied II» se compone de 4 cuartetos decasílabos, con rimas consonantes alternas (siendo agudas las pares).

- El «Lied III» se compone de 5 cuartetas, alternan dos disposiciones silábicas (7/7/6/6-6/6/7/7-7/7/6/6, etc.). Las rimas son asonantes, su disposición alterna también (aabb-abab, etc.).

- El «Lied IV» se compone de 4 tercetos (6/11/11 sílabas), con un complejo sistema de rimas: los hexasílabos repiten la asonancia «a-a», el último endecasílabo de cada estrofa lleva rima asonante también («e-a»), produciéndose una rima consonante entre el segundo terceto y el cuarto («sentencia», «inocencia»); el segundo endecasílabo de la segunda estrofa y de la cuarta riman («ía»).

\section{La canción de las figuras}

- $\mathrm{El}$ «Lied $\mathrm{V} »$ mezcla versos de diferentes medidas (oscilan entre 5 y 13 sílabas), aproximándose a la estructura de la silva impar, pero con unas pocas asonancias desperdigadas y una rima consonante (los dos últimos versos).

\section{Sombra}

- El «Lied VI» (bajo forma de diálogo) se compone de 4 cuartetas que mezclan versos de 6, 5, 4 y 3 sílabas, predominando los hexasílabos, con asonancia aguda en los pares (en «o») y dos casos de consonantismo («adiós» / «dos»; «corazón» / «son»).

— El «Lied VII»: son ocho pareados decasilábicos, aconsonantados. 
- El «Lied VIII» mezcla también versos de diferentes medidas (entre 5 y 11 sílabas), impares, salvo el primero (un octosílabo). En los versos impares se repite la asonancia «a-a», en los pares «e-o».

- El «Lied IX» está compuesto de seis estrofas de cuatro versos (mézclanse los heptasílabos y los decasílabos). Riman los versos pares de la siguiente manera, cercana al quiasmo: $1 \S$ «e-o» $2 \S$ «a-a» $3 \S \ll 0-a » 4 \S \ll a-o » 5 \S \ll a-a » 6 \S \ll e-0 »$.

Ese recuento confirma la gran variedad métrica adoptada por Eguren. Un análisis más detenido corroboraría, en mi opinión, la independencia de Eguren respecto a posibles modelos (su decasílabo, por ejemplo, no tiene esa «andadura» simétrica del de Bécquer, en el análisis de Carlos Bousoño (1963). La importancia numérica de los cuartetos (en cuatro de los diez lieder) recuerda quizás, aunque lejanamente, el antecedente alemán o becqueriano. Para Eguren, pues, el lied no es modélico: parece solamente sugerir, como lo indica Jean-Louis Backès a partir de un vasto elenco europeo y americano fin de siècle, un «mood», un «état d'âme» (1994: 238).

Lo que, en definitiva, parece proporcionar el lied, es una gran libertad, dentro de un sistema poético que puede ser calificado de «musical» ${ }^{5}$. Esta me parece ser la cualidad de un lied como el quinto, por cierto muy cercano a la prosa, desvinculado de algunos elementos tradicionales (rima, isosilabismo, patrones acentuales), pero que remite constantemente a lo metapoético, y que no por nada viene relacionado con un tipo de poesía de habla inglesa (los musing) defendido, en España, por Unamuno:

\footnotetext{
La canción del adormido cielo dejó dulces pesares; yo quisiera dar vida a esa canción que tiene tanto de ti.

Ha caído la tarde sobre el musgo del cerco inglés con aire de otro tiempo musical... («Lied V»)
}

5 En esto se relacionan modernismo y posmodernismo, las vanguardias rompen de manera más marcada con ese sistema «musical», cuyas posibilidades analizó finamente el joven Reyes de Cuestiones estéticas (1911). En todo caso, se trata de polos - no de diferencia radical - entre un sistema, el (pos)modernista, todavía atento a las categorías (ideales) armónicas y otro, el vanguardista, más atento a lo gráfico-espacial del lenguaje ( $c f$. su interés por la metáfora). 
$\mathrm{El}$ aspecto, voluntariamente vago, de un término como «mood», me parece útil, por lo menos en una primera aproximación, para marcar una especie de desemantización del material poético que está a la obra en los lieder de Eguren. Esa desemantización se nota, por supuesto, desde el título de cada pieza que se aleja de lo denotativo (en la relación título-texto) para apelar a una superestructura (la del lied, de los lieder), de tipo connotativo, basada, como he sugerido, en la idea de desplazamiento (lingüístico-cultural).

El lied citado en las líneas anteriores, las múltiples ocurrencias del término «canción» en los diferentes lieder egurenianos (a las que habría que añadir el campo léxico referido a lo musical), confirman una correlativa autonomía del material poético, más allá, o más acá, de cualquier referente. Lo que metafóricamente podríamos acaso llamar lo «poéticomusical» procede rítmicamente (antes que filológicamente) del empeño del lied, del ideal poético-musical del lied alemán. Eguren, dentro del marco ideológico de lo musical (no me cansaré de repetirlo, hasta cabría hablar de un ideal «eufónico»), extrema las posibilidades métricas, prescindiendo muchas veces de los patrones rítmicos, tanto desde el punto de vista estrófico (con esas estrofas que mezclan anisosilabismo y repartición original de las rimas), como desde el punto de vista interno (entre versos). Para tomar un ejemplo en este sentido: el último endecasílabo del primer lied no corresponde a un patrón métrico canónico: «y en la bruma hay rostros desconocidos» $(3 / 5 / 7 ? / 10)^{6}$.

El lied induce, pues, a una constante búsqueda musical, que se manifiesta en una diseminación de los paradigmas fonéticos. Las asonancias internas son múltiples, así en la segunda estrofa del primer lied: «nublados en la música azul», donde la «u» sirve de apoyo vocálico, reforzado a su vez por las consonantes ( $c f$. la pronunciación americana de la zeta), a imagen de lo que se había producido en la rima con «luz» (primera estrofa, con el otro apoyo de la líquida). El fenómeno se extiende a una estrofa entera, como la segunda del «Lied II»:

\footnotetext{
Y vense las obscurosas olas masteleros últimos cubrir, con el amor de las playas solas donde van las aves a morir.
}

6 El mismo esquema prosódico vertebra el verso «al dar sus adioses sobre la playa» ( «Lied V»). Por otra parte, tanto Henríquez Ureña (1961: 339) como Domínguez Caparrós (2000: 96) subrayan la originalidad prosódica del endecasílabo y del dodecasílabo (respectivamente) egurenianos. 
Subrayo aquí sólo algunas de las repeticiones más notables. Desde el principio se retoman elementos de la estrofa anterior (en particular la «V-» de «y el viento», «vesperal»), para anticipar el sistema vocálico-consonántico del cuarto verso («vense», «van», «aves») que crea en el lector la imagen sonora de la «nave», precisamente el significante desaparecido, naufragado. «La virgen nacarina», en la estrofa siguiente, tomará el relevo sonoro y semántico. La primera rima «olas / solas», viene anunciada también por la estructura fonética del verso entero, en particular a través del neologismo «obscurosas», frecuente en la poesía de Eguren. La rima se desborda de los límites del corte sintagmático («[obscurosas]s olas / [playa]s solas»), como para mejor sugerir la intensa contaminación prosódica. Idéntica repetición de una matriz que va más allá de los límites sintagmáticos se encuentra entre los versos tercero y cuarto («amor / a mor[ir]»). El segundo verso es otro ejemplo de iteración consonántica $(\mathrm{m} / \mathrm{st} / \mathrm{l} / \mathrm{s}-\mathrm{l} / \mathrm{t} / \mathrm{m} / \mathrm{s})$.

Pienso que el análisis podría extenderse a todo el poema a través del continuum prosódico-semántico y a buena parte de la obra del poeta, a un poema como «Pedro de acero» (Simbólicas), por ejemplo, que sería una buena ilustración de la teoría de los anagramas saussurianos. El último poemario, Rondinelas, donde aparece con más nitidez lo gráfico-espacial, se acerca también, como lo sugiere Estuardo Núñez (1932: 33) a lo jitanjafórico. Así en un poema como «Sonela»: «Vuela volón / el aluzón...», que parece una especie de desarrollo del material de un lied como el «Lied VI», de Sombra, con su «sin son, sin son». Eguren, en este sentido, sólo podría compararse con el César Vallejo de Trilce o, más cercanamente quizás, con el poeta de La rosa de la espinela, Martín Adán ?

El lied alemán, por supuesto, y sin que se apele por ello a ninguna relación directa, no desconocía el poder evocador de las aliteraciones, así en el ejemplo, quizás hiperbólico, del cuarto verso de «Die Rose, die Lilie...», de Heine, poema escogido por Schumann en su ciclo del Amor del poeta (Dichterliebe): «Die Kleine, die Feine, die Reine, die Eine». Del mismo modo, la regularidad acentual del lied (escúchese cómo se escande el verso «Es flüstern und sprechen die Blumen» del lied «Am leuchtenden Sommermorgen», del mismo ciclo, en la interpretación de Wunderlich) encuentra quizás un equivalente en las similicadencias de los lieder egurenianos ${ }^{8}$. Para retomar el ejemplo

7 Esto no significa equivalencia absoluta sino convergencia de algunos elementos poéticos.

8 La Ortometría de González Prada (1988) descansa igualmente en la combinación de cláusulas simétricas. 
anterior del segundo lied (con su admirable continuum «Schumann vesperal; / y distante»):

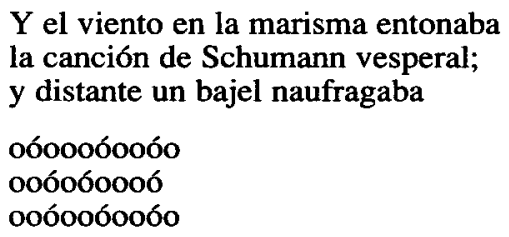

Otro fenómeno que se repite en los poemas del peruano, y que podría evocar, otra vez lejanamente, a la poesía alemana, es la torsión sintáctica. Si el lector recuerda las ocurrencias, en la poesía de Eguren, de la mención hecha a sus músicos preferidos (Schumann, Mendelssohn, Weber...), habráse dado cuenta del uso del hipérbaton. En realidad, es una constante, como puede verificarse en el «Lied IX». O bien, desde el último verso del «Lied I»: «que contemplan el árbol morir», estructura que parece retomada en el lied siguiente: «masteleros últimos cubrir» y que, antes que con el modelo sintáctico alemán, tiene quizás que ver con la poesía de Bécquer (sus rimas agudas proporcionadas por las flexiones verbales).

\section{CIRCULACIÓN DEL SENTIDO: CONTIGÜIDADES Y LECTURAS SERIADAS}

La contigüidad, más metafórica que metonímica, con los lieder alemanes, confirma que los propios lieder egurenianos construyen el marco de su recepción: dejan al lector-oyente en el fiel de la balanza, entre el sonido y el sentido. Al mismo tiempo, el dispositivo poético del lied, por contaminación y atracción, influye en la escritura, que deriva hacia lo musical. Ahora bien, el tipo de lectura que parece alentar el dispositivo musicalizante del lied (una lectura que no sea solamente analítica) no significa que no haya producción de sentido, sino que se invita, en cierta manera, a una lectura traslaticia, soslayada, que deje circular el sentido.

La coherencia interna de los lieder de Eguren descansa, sin duda, en cierta homología, una contigüidad con la tonalidad del lied alemán, su 
carácter elegíaco, nostálgico, que puede verificarse tanto en los ciclos de Schumann (el citado Dichterliebe o su Liederkreiss) como en los de Schubert (del Winterreise al Schwanengesang ). El elemento acuático, con otros más puntuales como la alusión al árbol («Lied $\mathrm{I} »)$ o a los buques fantasma («Lied III»), se relacionan también indudablemente con el imaginario germánico y la temática de los lieder. Ambos presentes, además, en las traducciones de González Prada o las poesías de Jaimes Freyre. Algunas traducciones de Pérez Bonalde ofrecen, igualmente, pistas interesantes que no puedo examinar aquí ${ }^{9}$.

Sin embargo no hay ninguna intertextualidad estable (arqueológica), sino ya una movilidad propiamente literaria en la «disposición» de los poemas egurenianos. Una multiplicidad de contigüidades posibles, como lo sugiere el «Lied VI» que adopta una forma dialogada: «-Cavas panteonero / tumba de dolor. / -Murió en la mañana / la virgen Sol [...]». Es la forma de la balada inglesa o alemana, por supuesto, pero entronca también - por el léxico y el tono nostálgicocon una tradición autóctona, como la del yaraví ${ }^{10}$.

Esas coincidencias evidencian una red compleja y móvil, las constantes alteraciones del dispositivo poético. Quisiera insistir, sin embargo, en otro aspecto que me parece fundamental para entender esa circulación del sentido a la que me refería. El hecho de haber puesto Eguren un número, que no un título, a sus lieder parece invitar, en efecto, a una lectura no solamente «musical» sino también seriada. Obviamente, el fenómeno viene anticipado estructuralmente por el llamado «ciclo» de lieder alemán (Liederkreiss). Quizás también por un poemario como el Intermezzo de Heine (a partir del que Schumann elabora, creo haberlo dicho, su Dichterliebe). Es lo que había intuido su clarividente traductor al francés, el poeta Gérard de Nerval:

Le poème intitulé Intermezzo [est] une suite de petites pièces isolées et marquées par des numéros qui, sans avoir de liaison apparente entre elles, se rattachent à la même idée. L'auteur a retiré le fil du collier, mais aucune perle ne lui manque (Heine, 1848: 19).

9 Pienso en traducciones de Pérez Bonalde, como las de «El caballero nocturno», de Uhland (1964: 181-182), «El triste» (42) o «Los dos hermanos» (43) de Heine, que ofrecen interesantes paralelos con algunos poemas egurenianos.

10 El yaraví andino, como el huayno, es una canción de origen quechua, de tema generalmente amoroso y melancólico. Garcilaso de la Vega, el Inca, recogió algunos de ellos, caracterizándolos como poesías de metro menor. La forma dialogada del «Lied VI» también tiene que ver con la canción popular. Esos elementos aparecen, por ejemplo, en las Baladas peruanas de González Prada. 
Ese juego entre continuidad (la imagen del collar) y discontinuidad (sus perlas) caracteriza también (hasta anímicamente) la construcción del Dichterliebe de Schumann. Por otra parte, el esquema narrativo del Amor del poeta es conocido y ejemplar: la felicidad primero, la pérdida de la amada después, luego la vuelta obsesiva del recuerdo que el poeta trata de enterrar simbólicamente en el último lied («Die alten bösen Lieder»). Puede decirse que las otras estructuras visibles del ciclo (las temporales en particular, con la presencia de las estaciones) dependen del esquema narrativo inicial.

Mi hipótesis en cuanto a los lieder egurenianos es, pues, la de la presencia subterránea (consciente o inconsciente) de ese modelo narrativo (que juega con lo continuo y lo discontinuo), actualizado de manera fragmentaria en su última etapa (el imposible retorno de lo perdido). Véamoslo a través de los cuatro lieder de Simbólicas (Anexo) un poemario «genéticamente» completo por la existencia de un manuscrito y de su edición bajo la dirección del poeta.

Hay diferencias importantes entre el libro y el manuscrito, en particular por lo que concierne al orden de los lieder. El primer poema del manuscrito se titulaba «Gondellied», ese poema cambia de título en la edición final, se le conoce ahora como «La dama I», y ocupa el rango 13 (en total hay 34 poemas). El manuscrito acababa con los tres lieder (el «Lied III», el «Lied I» y el «Lied IV» del poemario, respectivamente). El actual «Lied II» se titulaba «La muerta», y era el 14 del manuscrito. En la edición final, el «Lied I» es el primer poema del libro, el segundo ocupa el rango 16 , el tercero el 29 y el cuarto cierra el poemario (34).

¿Qué efectos surte la reorganización del conjunto? Parece primero confirmarse la voluntad de desemantización a partir de los títulos (desaparece el de «Gondellied» y «La muerta» se titula «Lied II»), pero se hace más visible la estructura global: el libro se abre por el «Lied I» y se clausura con el «Lied IV». El «núcleo final» (los actuales lieder III, I y IV, respectivamente) queda disuelto. La tensión entre fragmentación y continuidad me parece motivar esos cambios. Los lieder primero y cuarto constituyen el marco (generativo) del conjunto, podrían ser considerados incluso como manifestación del protocolo de lectura (musical) del poemario (¿de la obra?) y ser el testimonio de su relativa autonomía por su carácter «circular». Los lieder segundo (antes «La muerta») y tercero confirman el carácter especular y cerrado del conjunto. Volveremos a la disolución del núcleo final del manuscrito. La estructura métrica de dichos lieder confirma la creación de 
esos pares —el primer lied y el cuarto se componen de tercetos; el segundo y el tercero de cuartetos-, al mismo tiempo que, en los cuatro casos, se impone una continuidad general, por la persistencia de la asonancia inicial «a-a» («alba», «entonaba», «brava», «pasaba»).

Se crean así dos «microciclos» (lieder I y IV / lieder II y III), el primero de ellos se relaciona con lo terrestre, el segundo con lo acuático, etc. Existen otras numerosas relaciones dentro de cada uno: algunas palabras claves («bajel», «obscurosas», «mar», etc. por un lado; «ojos», «sangre/sangrando», «noche», etc. por otro); la presencia del tiempo («alba» / «noche») en los lieder I y IV; tiempo manifiestamente circular, como lo confirman los lieder II y III (naufragar-emerger / emerger-hundirse).

Con ello se agota la narratividad, cerrándose el movimiento cronológico: el infinitivo con que acaba el primer lied («morir») y el gerundio en el último verso del cuarto («sangrando»), semiotizan ese proceso casi atemporal que el verbo «volverse» (del «Lied III») materializaba semántica y gramaticalmente (por el reflexivo). El modelo (narrativo) de la balada deja paso a una estructura más abiertamente poética, en el sentido de Jakobson, por el retorno paradigmático. Eso repercute en no pocos de los otros lieder de Eguren, como en el «Lied IX» que distribuye los elementos métricos y léxicos de manera perfectamente circular.

Al mismo tiempo, varios elementos rompen la circularidad o problematizan una lectura autónoma. Así la conjunción inicial del «Lied II», que supone la continuidad musical ( YY el viento en la marisma entonaba»), una anterioridad indefinible. Esa misma ruptura se verifica con la distanciación, en el espacio del libro, entre el primer lied y el cuarto, antes reunidos en el manuscrito. Por ello el antecedente de «sus ojos» («Lied IV»), que parecía poder ser relacionado con el de «tus ojos» («Lied $\mathrm{I} »)$, resulta ahora más abstracto, se produce una como impersonalización que parece inducida por esos «rostros desconocidos» del primer lied. El «Lied IV», en todo caso, sigue hermético, los blancos inter-estróficos concretizan la serie de rupturas lógicas y temporales que se producen, al mismo tiempo que los paralelismos (donde lo fonético parece imponerse frente a lo gramatical, como en el primer verso de cada estrofa) mantienen la posibilidad de una relación entre las piezas del rompecabezas.

Los lieder de Eguren parecen, pues, a la vez fragmentos destacados de un ciclo y realización de dicha circularidad, pero nunca satisfacto- 
riamente. Los lieder primero y cuarto, este último en particular, representan momentos de una historia cuyos antecedentes desconoce el lector, la historia de una pérdida, sin duda, y que no se resuelve. Los otros dos lieder materializan la circularidad, como momento de otro movimiento más amplio (lo continuo musical de la conjunción inicial del «Lied II»), pero el cierre que éstos efectúan tampoco constituye una resolución (es un retornar a los cauces iniciales). En definitiva el sistema aparentemente cerrado, autónomo, se ve absorbido por los horizontes (también temporales) que se abren.

No hay asideros, límites fijos, para circunscribir esa «lejanía» esencial. En cierto sentido, se podría hablar de una espacialización «negativa» (volveremos sobre el término) del lenguaje poético egureniano. Es precisamente el tema de uno de los Motivos («La impresión lejana») del escritor:

La lejanía es una llamada innómina, una dilatación del espíritu, una palabra errante. [...] Amor de la mañana; la mañana viene de lo remoto y nos alcanza. La tarde es movimiento y despedida. La noche [...] se dilata en el misterio (1974: 337).

Mañana, tarde y noche temporalizan la inmensa mayoría de los lie$\operatorname{der}$ (y de la poesía) de Eguren. Fundan un espacio (un sentido) que se extralimita, se dispersa, aunque parezca seguir el orden (sucesivo) de lo musical. Si la pérdida hermana los cuatro lieder de Simbólicas, la presencia de una doble escena (superficie / profundidad) conlleva inmediatamente la imagen del símbolo y su duplicación, la esperanza de la recuperación del sentido. Sin embargo, los símbolos egurenianos son inexplícitos, truncos, es difícil atribuirles una salida, un sentido trascendente unívoco.

Los lieder de Eguren, antes que significar (en el sentido de remitir a un significado ubicable, ser «narrables»), emiten una serie de «señales», porque así lo reza el significante: «señales de muriente dolor», del «Lied I». Y si este significante parece diseminarse en «peñascal», lo hace objetivizando su función: señalar el lugar (y señalarse como causa) del naufragio, de la desaparición. Este es el papel que parecen desempeñar también las «gotas de sangre» del «Lied I», «las obscurosas estelas» del «Lied III» o el «cuervo incierto» del «Lied II» (extraña paloma de Noé o del Espíritu Santo, invertida en negrura).

Ese «lenguaje» también «incierto» («Lied III») manifiesta su movilidad, ahondando o vaciando el lugar que habita. En el resto del libro, 
poemas como «Las señas» con su «luz desierta» o «La tarda», «por la muerta avenida», retoman ese sistema de indicios de un enigma quizás sin solución. «Los canes, olfateando / en el viento la sombra de la muerta», del cuarto lied, efectúan el mismo recorrido, la misma búsqueda, por ese espacio cerrado-abierto ¿la «región atea» del poema «El dios cansado» de La canción de las figuras?

\section{LA MÚSICA, LA PALABRA}

Ese espacio-tiempo incierto, que se dilata, corresponde a aquél de la música tal como la concibe Eguren, «la música [...] lejanía en el tiempo» (1974: 337). Creo que ahora podemos entender mejor cómo se compenetran el lied (musical y seriado) y la poética de Eguren: la música cumple un papel «negativo» - «se diría la más negativa de las artes»- desde el punto de vista denotativo, pero resulta altamente productiva - «por su élan ferviente» (311). Permite que se cumpla la «in(de)terminación» — «movimiento interminado» (338) - que ambiciona la poética egureniana: «La obra de arte es un dictado misterioso. La voluntad lleva al fracaso» (308).

La música, es decir la pulsión aliterativa en el poema, lo continuo musical, es el otro polo energético de la textualidad egureniana: «la música es un presentimiento, la poesía una determinación» (246). Si ésta corre el riesgo de parecer «explicativa» (246), aquélla garantiza la libertad, transfiriendo tal libertad al lector-oyente, manifestando la disponibilidad, la movilidad esencial del sentido.

Los lieder seriados de Eguren tienden por ello a la vez a la clausura, a la vuelta del signo sobre sí mismo - símbolo manco, sin resolución dialéctica- y a la apertura — falta de límites, imposibilidad de una identificación definitiva-, puro goce y puro dolor.

Paradójicamente quizás, con ese movimiento continuo, el poeta vuelve a encontrar, de manera renovada, el movimiento de la balada en sus mejores ejemplos, los que escapan de la simple narratividad, como el «Erlkönig» de Goethe, que se cierra sobre su misterio. Ignoraremos, en el «Lied IV», si Alguien (¿culpable o inocente?) muere («la sombra de la muerta») o no («el florete durmióse en la armería»). Quizás los lieder egurenianos sean también el lejano y prolongado eco de los lieder alemanes, en el adiós: la mano que se mueve (i.e., hace una señal) 
en el lied «Aus alten Märchen winkt es» (Dichterliebe), las huellas que se extravían en la nieve del Winterreise. Caminos que se borran en un «ensueño blanquecino» ( Lied $\mathrm{I} »)$.

Es difícil imaginar una lectura que no sea analógica. Los lieder egurenianos responden también a ese requisito analógico: por los ecos que hay dentro de cada lied y que se prolongan entre los lieder, a su vez en contacto con una multitud de textos afines. Pero al mismo tiempo el dispositivo seriado crea la distancia: la analogía no puede ser sino un movimiento continuo (de lied en lied); las analogías puntuales sirven también para marcar las distancias, la irreductibilidad del poema. El dispositivo implica una lectura inacabable, inferencias múltiples. Implica también una orfandad esencial, la del sentido inmediato.

Los lieder de Eguren son a la vez totalmente nostálgicos y totalmente proyectados hacia el futuro. Se avisa: «no añores viejas albas / que el ayer es un ángel muerto» («Lied VIII»). O sea en un presente totalmente inestable: el de una lectura movida sin cesar por el impulso musical. El lector está en el umbral, en el filo del alba, entre la palabra y la música — «espacio ilímite» (1974: 338)— ¿un lugar utópico donde la palabra se volvería música? El piano, solo, con que concluye, y pues empieza, el Dichterliebe de Schumann. Los Lieder ohne wort de Mendelssohn. Un lugar de paso.

\section{Anexo: los cuatro lieder de Simbólicas (1911)}

Lied I

Era el alba, cuando las gotas de sangre en el olmo exhalaban tristísima luz.

Los amores de la chinesca tarde fenecieron nublados en la música azul.

\footnotetext{
Vagas rosas ocultan en ensueño blanquecino señales de muriente dolor.

$Y$ tus ojos el fantasma de la noche olvidaron, abiertos a la joven canción.

Es el alba; hay una sangre bermeja en el olmo y un rencor doliente en el jardín.
} 
Gime el bosque,

y en la bruma hay rostros desconocidos que contemplan el árbol morir.

\section{Lied II}

$\mathrm{Y}$ el viento en la marisma entonaba la canción de Schumann vesperal; y distante un bajel naufragaba en el insidioso peñascal.

$\mathrm{Y}$ vense las obscurosas olas masteleros últimos cubrir, con el amor de las playas solas donde van las aves a morir.

Y surgió la virgen nacarina desde el submarino panteón, y con la luz de ocaso declina y con una lánguida canción.

Sobre ella parado un cuervo incierto la guía en violeta navegar.

Hoy la mística blancura ha muerto con toda la tristeza del mar.

\section{Lied III}

En la costa brava suena la campana, llamando a los antiguos bajeles sumergidos.

$\mathrm{Y}$ con tamiz celeste y al luminar de hielo, pasan tristemente los bajeles muertos.

Carcomidos, flavos, se acercan vagando... y por las luces dejan obscurosas estelas.

Con su lenguaje incierto, parece que sollozan, a la voz de invierno, preterida historia.

En la costa brava suena la campana, y se vuelven las naves al panteón de los mares.

\section{Lied IV}

La noche pasaba; y al terror de las nébulas, sus ojos inefables reían la tristeza.

La muda palabra en la mansión culpable se veía, como del Dios antiguo la sentencia. 
La funesta falta

descubrieron los canes, olfateando

en el viento la sombra de la muerta.

La bella cantaba,

y el florete durmióse en la armería

sangrando la piedad de la inocencia.

\section{Referencias bibliográficas}

ABRIL, X. (1970). Eguren el obscuro. Córdoba [Arg.]: Universidad de Córdoba.

Areta Marigó, G. (1993). La poética de José María Eguren. Sevilla: Alfar. BACKÈs, J. L. (1994). Musique et littérature. París: PUF.

BALBín LuCAS, R. de (1962). Sistema de rítmica castellana. Madrid: Gredos, 1973.

BASADRE, J. (1928). «Elogio y elegía de J. M. Eguren». En Equivocaciones. Lima: La Opinión Nacional, 14-30.

BEssière, J. (1990). Dire le littéraire. Liège-Bruxelle: P. Mardaga.

Bousoño, C. (1963). «Los conjuntos paralelísticos de Bécquer». En Alonso, D. y Bousoño, C. Seis calas en la expresión literaria española. Madrid: Gredos, 177-218.

DíEz TABOAdA, J.M. (1958). «Eulogio Florentino Sanz, poeta de transición». Revista de literatura 25-26, 48-78.

Domínguez CAPARRós, J. (1988). Métrica y poética. Madrid: UNED.

- (1999). Estudios de métrica. Madrid: UNED.

- (2000). «El modernismo en la formación del verso español contemporáneo». En Areta Marigó, G.; Le Corre, H.; SuÁrez, M.; Vives, D. (ed). Ritmo(s), métrica(s), ruptura(s) en la poesía hispanoamericana. Madrid: Verbum, 87-110.

EgUREN, J. M. (1974). Obras completas. [Silva-Santisteban, R. ed.]. Lima: Mosca Azul.

FERRARI, A. (1993). «Manuel González Prada y la poesía alemana: creación y tradición». En Caminos hacia la modernidad. Homenaje a R. Gutiérrez Girardot. Frankfurt: Vervuert, 133-141.

GonZález Prada, M. Cantos de otro siglo (1979 [1867-1900]). Lima: UNSM.

- (1985 [1894 / 1946]). Pájinas libres. En Obras, tomo I, vol. 1. Lima: Copé.

- (1988). Ortometría. Minúsculas. Presbiterianas. Exóticas. Trozos de vida. Baladas Peruanas. En Obras, tomo III, vol. 5. Lima: Copé.

- (1989). Baladas. En Obras, tomo III, vol. 6. Lima: Copé.

HeINE, H. (1848). Intermezzo [trad. G. de Nerval]. París: Le Seuil-Les Belles Lettres, 1995. 
HeINE, H. (1873). Intermedio, Regreso y Nueva primavera [trad. y notas Fernández y González, M. M.]. Madrid: El Imparcial, 1878.

HenRíquez UReña, P. (1961). Estudios de versificación española. Buenos Aires: Universidad de Buenos Aires.

JAIMES Freyre, R. (1899). Castalia bárbara. Buenos Aires: J. Schürer-Stolle.

LeZAMA Lima, J. (1957). La expresión americana. La Habana: Letras Cubanas, 1993.

Maldonado Alemán, M. (1999). «La teoría de los sistemas y la historia de la literatura». Signa 8, 251-279.

Meschonnic, H. (1982). Critique du rythme. Anthropologie historique du langage. Lagrasse: Verdier.

NAVARRO TOMÁs, T. (1956). Métrica española. Barcelona: Labor, 1986.

NúNEZ, E. (1932). La poesía de Eguren. Lima: Compañía de Impresiones y Publicidad.

Pérez Bonalde (1964). J. A. J. A. Pérez Bonalde. Caracas: Colección Clásicos Venezolanos, tomo 2.

Ureta, A. (1929). «Poesías, por J. M. Eguren». En Silva-Santisteban, R. (1977) (ed.). J. M. Eguren. Aproximaciones y perspectivas. Lima: Universidad del Pacífico, 81.

Urrutia, J. (1995). Poesía española del siglo XIX. Madrid: Cátedra. 